\title{
Urdimento
}

Revista de Estudos em Artes Cênicas E-ISSN: 2358.6958

\section{O espaço cênico como uma relação quiasmática}

\author{
Paulo Vinícius Alves
}

\section{Para citar este artigo:}

ALVES, Paulo Vinícius. O espaço cênico como uma relação quiasmática. Urdimento, Florianópolis, v. 1, n. 40, mar./abr. 2021.

de) DOI: http:/dx.doi.org/10.5965/1414573101402021e0204

Este artigo passou pelo Plagiarism Detection Software | iThenticate 


\title{
Resumo
}

Este artigo propõe estabelecer relações diretas entre a fenomenologia de Merleau-Ponty, mais especificamente com a noção de quiasma, e o espaço cênico teatral, através da revisão de alguns autores e algumas situações cênicas pensadas especialmente para tais relações. A partir de noções filosóficas, com exemplos comentados por Merleau-Ponty, como a relação entre figura e fundo, por exemplo, consideramos a importância do ponto de vista do espectador, tomado como elemento de efetivação da problemática fenomenológica, já que a relação do espetáculo com o espectador é um elemento fundante da poética teatral contemporânea.

Palavras-chave: Cenografia. Espaço relacional. Quiasma. Espaço cênico. Fenomenologia.

\section{The scenic space as a chiasmatic relationship}

\begin{abstract}
This article proposes to establish direct relations between Merleau-Ponty's phenomenology, more specifically with the notion of chiasma, and the theatrical scenic space, through the review of some authors and some scenic situations thought especially for such relations. Based on philosophical notions, with examples commented by Merleau-Ponty, such as the relationship between figure and background, for example, we consider the importance of the viewer's point of view, taken as an element of effectuation of the phenomenological problem, since the relation of the spectacle with the viewer is a founding element of contemporary theatrical poetics.
\end{abstract}

Keywords: Scenography. Relational space. Chiasma. Scenic space. Phenomenology.

\section{El espacio escénico como relación quiasmática}

\section{Resumen}

Este artículo propone establecer relaciones directas entre la fenomenología de MerleauPonty, más concretamente con la noción de quiasma, y el espacio escénico teatral, mediante la revisión de algunos autores y algunas situaciones escénicas pensadas especialmente para tales relaciones. Partiendo de nociones filosóficas, con ejemplos comentados por MerleauPonty, como la relación entre figura y fondo, por ejemplo, consideramos la importancia del punto de vista del espectador, tomado como elemento de efectuación del problema fenomenológico, ya que la relación del espectáculo con el espectador es un elemento fundacional de la poética teatral contemporánea.

Palabras llave: Escenografía. Espacio relacional. Quiasma. Espacio escénico. Fenomenología.

${ }^{1}$ Professor mestre da área de tecnologias da cena, principalmente nas disciplinas de cenografia, figurino e design cênico. É artista atuante nas áreas de cenografia, direção de arte e figurino. pvateatro@gmail.com

(6) http://lattes.cnpq.br/0117489287872118 (iD) https://orcid.org/0000-0002-1179-8092 
A coisa é grande se meu olhar não pode envolvê-la; é pequena, ao contrário, se ele a envolve amplamente, e as grandezas médias distinguem-se umas das outras conforme, em distância igual, elas dilatam mais ou menos meu olhar ou dilatam igualmente em diferentes distâncias.

(Merleau-Ponty)

É possível pensar que uma encenação teatral possa ser a realização de uma relação quiasmática, tal como estabeleceu o filósofo francês Merleau-Ponty? Poderia o espaço cênico teatral ser compreendido e ter o seu conceito expandido a partir do entendimento da noção de Quiasma? Nessa perspectiva, pensamos sobre o espaço cênico como um entrelaçamento entre sujeitos e espaço.

O espaço relacional no teatro é experimentado efetivamente, no decorrer da duração que se estabelece na relação entre o ator e o espectador, um espaçotemporal. A experiência estética no teatro é também carnal, primeiramente corporal, pois a percepção é uma pré-interpretação das nossas relações com o mundo e, antes de ser um entendimento intelectual, o encontro possibilitado pela percepção é um aprendizado físico e sensorial, mútuo, obtido através de uma relação cinesférica².

$\mathrm{Na}$ expansão das suas proposições, anos depois de escrever a obra Fenomenologia da percepção (2006), Merleau-Ponty vai prolongar a ideia da reversibilidade com um conceito mais amplo sobre essa temática do entrelaçamento. Trata-se da noção de Quiasma³, como esclarece Falabretti (2012, p. 219):

Em O Olho e o espírito, na análise da experiência do pintor, a reversibilidade manifesta uma nova possibilidade; é alargada para o todo corpo; da mão para o olho, do tocar para o ver. A reversibilidade é o quiasma - o entrecruzamento - entre o corpo e a carne do visível. O

\footnotetext{
2 "O espaço cinesférico ou cinesfera (kinesphere) é um termo criado por Rudorf Laban para denominar os espaços ao redor do corpo que delimitam o movimento. A cinesfera é um espaço virtual gerado tanto por si próprio (na linha de alcance do seu movimento) quanto por outro indivíduo ou objeto que estabelece o campo possível de uma pessoa" (Scialom, 2017, p. 231).

${ }^{3}$ O Quiasma, diz Merleau-Ponty, "faz com que pertençamos ao mesmo mundo, - um mundo que não é projetivo, mas que realiza a sua unidade através das incompossibilidades tais como a de meu mundo e do mundo do outro. [...]. O Quiasma no lugar do Para Outro: isso quer dizer que não há apenas rivalidade euoutrem, mas, co-funcionamento. Funcionamos como um único corpo" (Merleau-Ponty, 2012, p. 200).
} 
corpo do pintor é um vidente-visível, ele olha e participa do mundo. Toda a filosofia do pintor - a expressão pictural que está na sua obra - nasce da visão e explica a experiência da reversibilidade, pois o artista não se distingue entre ver as coisas e ser visto por elas. A potência motora do corpo e a sua ligação carnal com o mundo, encontram na pintura a sua fórmula mais profunda. A pintura é um gesto corporal, nasce do próprio corpo, da visão e das mãos do pintor.

Podemos entender que a noção de relação foi tratada por Merleau-Ponty em duas camadas relacionais. Na primeira camada o ponto relacional está justamente no entrelaçamento do corpo com o corpo, sendo tocante e tocado, ao mesmo tempo, produzindo conhecimento na articulação dos nossos sentidos. Porém, a relação de ver e ser visto está inserida na segunda camada de relação, onde o corpo se relaciona com o mundo ou, se preferirmos, quando o corpo se relaciona com o outro à distância, pois ver é, também, sentir a confluência de todos os sentidos. Segundo Falabretti, é justamente na experiência com o outro que Merleau-Ponty vai prolongar a relação de entrelaçamento (Quiasma).

Entre o eu e o outro, entre sujeito e objeto, entre passividade e atividade, na dimensão do sensível, não há qualquer distinção de natureza reflexiva, eles participam um do outro. Além disso, mais do que um índice de familiaridade entre o corpo, as coisas e o outro o que encontramos é a continuidade e o entrecruzamento tecido pelo sentir: a carne do mundo. (Falabretti, 2012, p. 209).

A relação de participação de um no outro, sujeito e objeto, conforme MerleauPonty apresenta a noção de reversibilidade, vai ser radicalizada com a noção de quiasma, pois vai além de sentir e ser sentido pelo mundo ou marcar essas diferenças. Quiasma é a noção de continuidade, a noção do tecido entre mim e o mundo, onde somos parte integrante do mesmo tecido do mundo.

Visível e móvel, meu corpo está no número das coisas, é uma delas; é captado na contextura do mundo, e sua coesão é a de uma coisa. Mas já que vê e se move, ele mantém as coisas em círculo à volta de si; elas são um anexo ou um prolongamento dele mesmo, estão incrustadas na sua carne, fazem parte da sua definição plena, e o mundo é feito do próprio estofo do corpo. Estes deslocamentos, estas antinomias são maneiras diversas de dizer que a visão é tomada ou se faz do meio das coisas, de lá onde um visível se põe a ver, torna-se visível por si e pela visão de todas as coisas, de lá onde, qual a água-mãe no cristal, a indivisão do 
senciente e do sentido persiste (Merleau-Ponty, 1984, p. 89).

Tudo isso Merleau-Ponty entendeu num primeiro momento como a lógica da percepção e num segundo momento como uma relação ontológica de que o espectador e a obra são parte do mesmo tecido, sendo um o prolongamento do outro. Ele sai da experiência do corpo, da subjetividade, e vai para a experiência do quiasma para o mundo. Essa é, portanto, uma experiência centrada na visão4 . Tal prolongamento é o que entendemos como o entrelaçamento, conforme explica Falabretti (2012, p. 221):

Em O Visivel e o invisível, a experiência das sensações duplas manifesta uma nova possibilidade. Se o corpo na Fenomenologia da percepção deixou de ser um objeto entre os objetos, em O visível e o invisivel ele não é mais pensando no horizonte de uma filosofia da subjetividade. É possível encontrar nos corpos, no mundo, no outro uma espécie de deiscência - abertura das coisas ao sentiente-sentido - como se as coisas que toco e sinto, simultaneamente, realizassem em mim o tocar e o sentir. O corpo abre-se em dois, deixa de ser aquele que percebe e sente para, também, ser percebido e sentido. Como está na última parte de o Visível e o invisível - O entrelaçamento, o quiasma - entre a mão que toca e aquela que é tocada, entre o corpo e o mundo não existe passagem, mas abertura e invasão, as coisas se entranham no corpo e, também, o corpo nas coisas.

É como se Merleau-Ponty dissesse que no ato perceptivo nós interrogamos as coisas do mundo e elas nos interrogam ao mesmo tempo, pois:

O entrelaçamento do corpo com mundo é uma operação da visão que nasce e explica a nossa condição sentiente-sentido. Todos os problemas da pintura, diz Merleau-Ponty, estão dados nessa relação, uma verdadeira comunhão entre o corpo e o mundo. Todavia, essa operação não é material, não é da ordem da coisa-objeto, mas das modulações sensíveis que conferem visibilidade ao visível: qualidade, luz, cor, profundidade etc. Todos esses índices da visibilidade, não estão no sujeito, não nascem da consciência, não são uma ilusão de ótica, não estão presos às coisas ou limitados ao corpo próprio. Esses emblemas da visibilidade se comunicam com o corpo que os acolhe e, também, se faz visível por

\footnotetext{
${ }^{4}$ Nesse sentido, todas as questões da pintura e da própria fenomenologia figuram no fenômeno da visão: o que é a profundidade, o que é a luz, o que é espaço, o que são as coisas, o que é outro etc. Além do mais, esse poder da visão de se alojar no pré-reflexivo, na camada anterior a todas as abstrações faz com que o nosso corpo seja ao mesmo tempo vidente e visível. Na visão em ato, o corpo próprio invade as coisas, domina os segredos do visível, como, também, é invadido, é visto pelas coisas. O corpo, através da visão, tem esse poder de ver e ser visto, de ser carne e participar da carne do mundo (Falabretti, 2012, p. 221).
} 
meio deles. Esse equivalente interno, essa meditação carnal de uma dupla presença, também desperta um rastro de visibilidade que une um corpo ao outro; realiza a comunhão entre duas visões e tem o poder de fazer com que um outro olhar reencontre os mesmos motivos que sustentam uma inspeção pessoal do mundo. A visão, portanto, é movimento de encontro entre o vidente e o visível (Falabretti, 2012, p. 219).

Sendo a visão o sentido de extrema importância para a efetivação do entrelaçamento entre o espectador e a encenação, olhamos para o formato de espaço cênico que se funda no interior da caixa cênica no teatro à italiana para pensarmos um primeiro nível de relação quiasmática, pois, "a visão é uma abertura para o ser que é presença e ausência, visível e invisível na medida em que as coisas estão ali, mas há uma postura do corpo que quer ver, uma experiência muda que suscita uma vontade de expressão" (Araújo e Codina, 2007, p. 17).

A literatura produzida sobre o teatro, comumente nos informa que sentado numa poltrona do teatro, frente à boca de cena do palco à italiana, o espectador assiste ao espetáculo passivamente. Ora, de um ponto de vista fenomenológico, o espectador atento não se torna passivo nem mesmo neste formato, pois, olhar é vivenciar. De um lado a encenação já previu que o espectador assistiria à encenação desta maneira, portanto tudo já foi antecipadamente pensado para esse ponto de vista específico, para essa perspectiva frontal da visão. Todos os elementos cênicos, espaciais e visuais foram pensados a partir dessa formulação. A experiência estética é sempre sobre o corpo do sujeito. Por outro lado, o espectador experimenta sob o seu ponto de vista como se desenvolvem as cenas apresentadas, estabelece novos significados para o que foi visto, encontrando outros elementos que não estavam dados inicialmente na montagem. Diversos fatores da encenação se encarregam de manter o espectador ativo durante toda a apresentação, formulando reflexões e conceitos, vivenciando sensações corporais, mesmo sentado na sua poltrona. A cenografia, por exemplo, pode proporcionar um maior ou menor grau de tridimensionalidade para o movimento do ator sobre o palco.

A experiência de um espectador atento no evento teatral é única e reveladora. Dessa maneira, cada um dos espectadores irá experimentar de uma maneira 
muito individual a relação, na medida em que também estabelecerá os seus significados. O filósofo Georges Didi-Huberman (2010, p. 66) 5 nos diz que "há uma experiência, logo há experiências, ou seja, diferenças. Há, portanto, tempos, durações atuando em ou diante desses objetos supostos instantaneamente reconhecíveis".

A relação quiasmática no interior de um teatro à italiana também pode ser pensada através do recurso da iluminação cênica. A iluminação pode exercer suas diferentes funções ao destacar algum elemento específico ou escondê-lo num outro momento para movimentar a relação de figura-fundo nas cenas apresentadas. Quando pensamos numa relação de figura-fundo pensamos, de certo modo, em uma bidimensionalidade feita com diferentes planos, ou seja, um plano frontal com diferentes distâncias do observador, como esclarece Arnheim (2005, p. 218):

\begin{abstract}
A bidimensionalidade como sistema de planos frontais é representada na sua forma mais elementar pela relação figura-fundo. Não se consideram mais que dois planos. Um deles tem que ocupar mais espaço do que o outro e, de fato, tem que ser ilimitado; a parte imediatamente visível do outro tem que ser menor e confinada por uma borda. Uma delas se encontra na frente da outra. Uma é a figura, a outra o fundo.
\end{abstract}

A relação de figura-fundo no espetáculo é muito importante para pensarmos a experiência da visão. Observando as figuras ambíguas da Gestalt ${ }^{6}$, tomando como exemplo a figura que apresenta ao mesmo tempo uma taça (ou cálice) e duas faces (ou perfis). É interessante observar que não está no nosso poder absoluto, como sujeito que olha, determinar as faces independentemente da taça e, consequentemente, também não está no nosso poder absoluto determinar a

\footnotetext{
${ }^{5}$ Georges Didi-Huberman, que é tanto um historiador quanto um filósofo da arte, herdou os liames ontológicos que a fenomenologia merleau-pontyana ou a psicanálise lacaniana sempre estabeleceram com a arte (Stéphane Huchet no prefácio da edição brasileira da obra O que nos vemos, o que nos olha de DidiHuberman).

${ }^{6}$ Em poucas palavras, a psicologia da Gestalt - assim como sucedeu a outros discursos no início do século XX - pôs em dúvida que nossa experiência estivesse orquestrada por um único articulador que, em termos gerais poderíamos chamar de Ego. [...]. Eis por que a análise experimental do comportamento, a psicanálise e a psicologia da Gestalt, porquanto suspendem o governo do mental, da consciência e do cerebral, respectivamente, figuram, para Merleau-Ponty, como promessas de uma mudança no modo de se compreender o vivido. [...]. Gestalt, portanto, designa aqui não somente a ideia de um todo espontâneo, mas, também, uma forma de relação entre as partes envolvidas, cuja nota característica é justamente a ausência de síntese (Müller, 2015, p. 360 - 263).
} 
taça independentemente das faces. Se nos concentramos na taça, a parte das faces vai sumindo aos poucos, mas ela nunca desaparece absolutamente. Basta titubearmos um pouco para que a figura comece a se embaralhar e a taça novamente se impõe. Essa relação de figura-fundo mostra como a nossa visão sensorial de mundo, a nossa percepção não é um 'querer ver', mas um acontecimento sempre relacional, com variáveis que independem da nossa vontade.

A percepção do espectador também depende da sua posição na plateia, da luz que incide sobre a cena, da perspectiva do seu olhar ou das diferentes sensações experimentadas, de modo que a figura ambígua, no qual o fundo se afasta e o ator se revela. Portanto, a percepção pode ser também um viés bastante significativo para a recepção de um acontecimento cênico no palco à italiana, no qual até mesmo os atores podem estar presentes como parte de uma construção ambígua, que hora se revela diante da luz e hora se confunde com a escuridão do palco.

As inúmeras investigações do fenômeno figura-fundo destinam-se normalmente para explorar as condições que determinam qual das duas formas se encontra na frente. A situação é ambígua com mais frequência do que se poderia superar. [...]. Já me referi ao cálice que pode ser percebido como espaço vazio entre dois perfis - um artifício que recentemente encontrou uma nova aplicação quando alguém descobriu que a folha vermelha de bordo da nova bandeira canadense poderia ser vista como o fundo vazio entre dois perfis brancos zangados, liberal e conservador, investindo um contra o outro. Tais padrões ambíguos se aproximam de um estado de multi-estabilidade (Arnheim, 2005, p. 218).

O espaço cênico frontal, no teatro à italiana, pode ser pensado através da lógica de uma relação figura-fundo, ambíguo, que não é fixo, único, tornando-se uma coisa só para o espectador. Ao contrário, ele é vivo de relações corporais e significação, através de imagens vistas, como nos inspira Merleau-Ponty. Portanto, um espectador não será absolutamente passivo no evento teatral, nem mesmo diante da frontalidade e da imobilidade do teatro à italiana. Através da imagem, experimentamos relações de proximidades e distâncias em relação ao sensível. 
Indo para um outro nível de relação, a encenação, quando acontece num espaço cênico alternativo, possibilita outras formas de imersões do espectador no espaço cênico. A sensação de estar com o corpo todo no lugar da cena, vivenciando relações físicas com o outro, seja o ator, um outro espectador ou o próprio espaço, pode ser uma experiência intensa e reveladora, muitas vezes. Esta é uma maneira diferente de contato entre os corpos e objetos presentes, uma outra maneira para a formação de quiasma.

O corpo do ator é um dos principais discursos da cena e o corpo do espectador é o principal canal de recepção do conteúdo não verbal. Dessa forma, diferentes experiências teatrais, ocorridas principalmente na segunda metade do século XX, preconizaram o caráter pós-dramático do teatro, conforme sistematizou Hans-Thies Lehmann na obra O Teatro Pós-Dramático. Sobre essa conceitualização do pós-dramático, Azevedo (2010, p. 135) escreveu:

O teatro pós-dramático é um teatro que acontece em terrenos movediços, um teatro que propõe enigmas comuns, a serem decifrados em comunidade, posto que nos tornamos cúmplices uns dos outros durante seus eventos, e dessa cumplicidade nascem traços de união, referências a uma mesma comunidade do já vivido, do compartilhado. Nesse sentido, esse tipo especial de teatro propõe uma nova relação com seu público: são relações de convivência em que regras da sociedade podem ser substituídas por outras, estas válidas tão somente para a realidade inventada da cena. E o corpo do ator, em seu despojamento e presença, exige daquele que lhe é próximo um desconforto de máscaras que desejam ser tiradas ou o desespero de não saber tirá-las. De qualquer maneira, esse é um teatro de incremento de consciências pela ampliação da percepção, no qual o corpo de cada um de nós, seja o que atua ou aquele que responde a essa atuação, sente uma necessidade de enfrentamento de seus próprios fantasmas, das linhas de seu corpo, dos poros arrepiados de sua pele, de sua imobilidade ou movimento compulsivo.

Um exemplo hipotético que poderia ser vivenciado no espaço cênico, no sentido de espaço vivido, de entrelaçamento, é uma relação corporal na qual o espectador se relacione com uma espacialidade específica, definida pela encenação, como num canto de um lugar ou de frente para um grande e alto muro. Nesse sentido, propomos aqui relações entre as proposições de Merleau- 
Ponty e as proposições do filósofo Gaston Bachelard ${ }^{7}$. A relação física com um canto de paredes foi tratada por ele no ensaio $A$ poética do espaço ${ }^{8}$. Nessa obra, o autor afirma que através do espaço se pode chegar a uma "fenomenologia da imaginação" ". Escolhemos a passagem do canto para pensarmos hipoteticamente relações permeadas no espaço cênico. Para o autor, todo canto de uma casa, ou seja, todo ângulo de um aposento, qualquer espaço reduzido onde possivelmente gostamos de estar, de confabular com nós mesmos, é para a imaginação uma "solidão", uma situação de privacidade e de introspecção. Estar protegido por duas paredes angulares é ter também o controle e a limitação do olhar, pois, estando de costas para o canto nos preocupamos em ver apenas o que está a nossa frente. Como escreveu Costa a respeito dessa passagem em Bachelard:

O canto representa a imobilidade do ser que se irradia por um aposento imaginário em torno do corpo físico. Esse corpo se imagina protegido, escondido, refugiado pelas duas barreiras congruentes que são a parede, embora o ângulo de abertura represente a porta de acesso a, ainda presente, vulnerabilidade do ser (Costa, 2016, p. 42).

Diante disso, "a consciência do ser em paz no seu canto propaga, ousamos dizer, uma imobilidade. A imobilidade irradia-se. Um aposento imaginário se constrói em torno do nosso corpo que se acredita bem escondido quando nos refugiamos num canto" (Bachelard, 1974, p. 287). A espacialidade do canto na obra de Bachelard está inteiramente associada à noção de "casa”, pois, conforme observou Bollnow (2008, p. 142):

\footnotetext{
7 “Para além de filósofo, crítico e epistemologista, Bachelard era cientista e poeta. A publicação de suas obras revela essa oscilação de interesses: a Filosofia das Ciências, a Lógica, a Psicologia e a Poesia. Seus trabalhos no domínio da Epistemologia continuam a ter grande relevância dos problemas científicos contemporâneos." (Moreira, 2004, p. 30).

8 Sobre a Poética do Espaço: "No presente livro, nosso campo de exame tem a vantagem de ser bem delimitado. Isso porque pretendemos examinar imagens bem simples, as imagens do espaço feliz. Nessa perspectiva, nossas investigações mereceriam o nome de topofilia. Visam determinar o valor humano dos espaços de posse, dos espaços defendidos contra forças adversas, dos espaços amados. O espaço percebido pela imaginação não pode ser o espaço indiferente entregue à mensuração e à reflexão do geômetra. É um espaço vivido. E vivido não em sua positividade, mas com todas as parcialidades da imaginação." (Bachelard, 2000, p. 19).

${ }^{9} \mathrm{O}$ autor afirma que através do espaço se pode chegar a uma fenomenologia da imaginação, ou seja, conhecer a imagem em sua origem, em sua essência, sua pureza. Com essa afirmação, Bachelard, que é um fenomenólogo, mostra-se partidário dos estudos interdisciplinares, unindo Literatura, Filosofia e Psicologia (Lucena, 2007, p. 1).
} 
Segundo Bachelard, o sentimento ancestral da vida que a casa transmite ao homem é o sentir-se bem pela presença de um abrigo. Ele se sente bem num sentido imediato, no calor de seu ninho. Este lhe dá uma "alegria de viver" bem elementar, na qual a pessoa se sente aparentada com o animal.

Estar fisicamente protegido, imóvel, nos permite também descansarmos, pararmos para refletir sobre os acontecimentos, estar sob certa proteção, pois "inicialmente, o canto é um refúgio que nos assegura um primeiro valor de ser: a imobilidade. Ele é a certeza local, o local próximo da minha imobilidade." (Bachelard, 1974, p. 287).

Um canto, ao contrário, também pode se tornar um lugar opressivo, estar pressionado, encurralado por duas paredes ao fundo, tendo na nossa frente um possivel opressor. Dessa maneira, o canto é para a imaginação um desconforto, pois tudo depende da orientação, como esclarece Falabretti (2009, p. 172):

Podemos dizer que o corpo habita um "nível espacial primordial", na medida em que se situa no mundo em função de um contato intermitente entre as suas intenções motoras e as solicitações da paisagem. Assim, o corpo escolhe uma orientação, envolve e é envolvido em uma orientação espacial. Nesse sentido, o corpo através de sua potência intencional dialoga com o mundo, pois o mundo não deixa de solicitar ao corpo um lugar, uma orientação que está, ao mesmo tempo, no poder do corpo de elaborar. Portanto, é desse modo dialético que precisamos ler a orientação espacial, sempre assentada em um "nível espacial" primordial que precede todos os outros níveis e, a partir do qual, a experiência perceptiva se desdobra.

Uma determinada cena teatral poderá instaurar-se como um elemento de opressão, por exemplo, e, dessa maneira, pode nos remeter à memória, ao lembrarmos de passagens da infância e reviver antigas emoções guardadas.

A imagem da criança encolhida no canto confronta-nos com a forma como a educação infantil é concebida pelos adultos: impositiva e violenta - seja essa violência física, com as surras, ou simbólica, com gritos e ameaças. Ao lermos a palavra casa os fonemas logo nos remontam a uma saudade, uma memória embotada, um estilhaço da infância. Ao lermos canto, somos levados à estreiteza do ângulo no qual o menino se encolhe amedrontado e é essa a força da imagem poética levantada por Bachelard (Costa, 2016, p. 44). 
A fenomenologia da imaginação, praticada por Bachelard, lida com a potência de uma sensação acionada por uma imagem de um lugar. Acionar antigas lembranças e sensações guardadas nos espectadores por meio do espaço cênico faz da experiência teatral uma relação potente, na qual os conceitos tematizados pela fenomenologia se tornam momentos de uma vivência artística e humana, pois, como esclareceu Merleau-Ponty (2006, p. 557), "quando evoco um passado distante, eu reabro o tempo, me recoloco em um momento em que ainda comportava um horizonte de porvir fechado, um horizonte de passado próximo hoje distante". Ao lidar com lembranças e sensações guardadas, o espectador poderá inclusive resinificar a dramaturgia apresentada e estabelecer relações mais intensas com o evento teatral.

O verbo "habitar" é muito frequente na obra A poética do espaço de Bachelard quando se refere à relação do sujeito com sua casa. O conceito de habitar, conforme ele nos apresenta, está muito próximo ao conceito de vivenciar como Merleau-Ponty nos apresenta na noção de corpo próprio. Dessa maneira, "a casa vivenciada não é uma caixa sem vida. O espaço habitado transcende ao espaço geométrico" (Bachelard, 1974 p. 78).

Outros espaços poderão ser tomados hipoteticamente como exemplos de uma experiência fenomenológica entre espectadores e a encenação. Ao imaginarmos uma grande parede, por exemplo, como um grande muro alto, ficamos pensando nas possíveis relações estabelecidas tendo de um lado do muro os espectadores e de outro lado, distante dos seus olhares, os atores e suas respectivas cenas, que serão ouvidas através do muro alto, mas não visualizadas. Podemos também pensar numa outra encenação específica, na qual os espectadores serão separados pelo grande muro.

A visão bloqueada, o acesso restrito, a barreira que nos impede de conhecer o que está oculto, o que podemos ouvir, mas o que não podemos ver faz com que essa espacialidade do grande muro coloque os espectadores em situações conflitantes de sensações em relação ao espetáculo. Nessa perspectiva, a corporeidade, de atores e espectadores, é afrontada pelo espaço. 
O bloqueio espacial, a barreira, pode estabelecer outras relações internas a ver com a questão da distância. O outro lado está logo ali, do outro lado do grande muro, porém a distância que deveremos percorrer para chegar até o outro lado da barreira, movimenta muitas outras questões relativas ao sujeito quanto à vivência desse espaço específico.

A luz, por sua vez, pode ser um dos principais elementos relacionais e dramáticos no espaço cênico. São inúmeras as possibilidades de propor relações visuais entre espectadores e atores, por exemplo. O próprio espaço cênico pode sofrer alterações físicas com o movimento, a intensidade ou a angulação da luz. E, nesse sentido, salientamos, não falamos da iluminação cênica apenas como elemento estético, mas como profundo elemento relacional entre sujeitos e objetos, pois, como escreveu a iluminadora Cibele Forjaz (2010, p. 171):

Através do movimento da luz, podemos transformar o espaço e o tempo da ação, relacionar elementos presentes na cena ou isolá-los, separandoos no espaço ou no tempo; quebrar, interromper ou impulsionar a ação dramática; reforçar ou revelar a ilusão; mudar o código de leitura da "realidade" para a da "ficção" e vice-versa; revelar a presença do espectador no mesmo local dos atores, o que evidencia o ato teatral, ou, ao contrário, enviá-lo para outra dimensão através de atmosferas oníricas; tudo isso, no tempo de ascender ou apagar uma lâmpada.

A fenomenologia de Merleau-Ponty pode nos instigar a propor, por exemplo, enquanto criadores do teatro, uma espacialidade relacional no qual o espectador sinta no decorrer da encenação a mudança de temperatura do ambiente. Tal recurso poderá ser executado com o auxílio de aquecedores ou resfriadores de ar, conforme a proposta dramatúrgica dessa encenação que estamos imaginando. Outro recurso muito eficaz para instigar a mudança de temperatura no corpo do espectador é uma atmosfera climática orquestrada pelo uso da cor, neste caso, uma cor luz'10. Por exemplo, para se conseguir uma temperatura quente podemos nos utilizar de refletores que propagam uma intensa luz vermelha, forte, capaz de tingir todo o ambiente formado por recursos cenográficos, atores e espectadores.

${ }^{10}$ Cores-luz são as que provêm de uma fonte luminosa direta, estudadas mais nitidamente na área da Física, com vasto emprego na sociedade contemporânea. São elas que iluminam as nossas vidas, como a luz do sol, a de uma vela, a de uma lâmpada ou de uma descarga elétrica (Pedrosa, 2006, P. 28). 
Todos os elementos presentes são tingidos por tal atmosfera, alcançada pela propagação de luz vermelha. O contrário também será possível, ou seja, a propagação de uma luz de cor fria, como o azul, tingindo intensamente o ambiente pode esfriar completamente a atmosfera do espaço cênico. Mas, a experiência com a cor nem sempre é esclarecida absolutamente pelas teorias da física, como esclareceu Arnheim (2005, p. 358):

\begin{abstract}
Ninguém nega que as cores carregam intensa expressividade, mas ninguém sabe como tal expressividade ocorre. Admite-se, é amplamente aceito que a expressividade se baseia na associação. Diz-se que o vermelho é excitante porque nos faz lembrar fogo, sangue e revolução. 0 verde suscita os pensamentos restauradores da natureza, e o azul é resfrescante como a água. Mas a teoria da associação não é, neste caso, mais esclarecedora do que as outras áreas. O efeito da cor é demasiadamente direto e espontâneo para ser apenas o produto de uma interpretação ligada ao que se percebe pelo conhecimento.
\end{abstract}

A cor, para Merleau-Ponty, tem uma função ontológica no nível do mundo percebido, pois o mundo se torna apto para representar todas as coisas, uma vez que a relação entre corpo e mundo é relativa à sensibilidade e aos sentidos, na medida em que o interior de um se propaga indefinidamente no outro. A cor é uma irradiação do ser, pois, como coloca Cardim (2009, p. 122):

Se as próprias cores são dimensões é porque, por um lado, elas são certa espécie de ser que se impõe como determinada particularidade, por outro, uma abertura, uma dimensão que aparece para mais de uma pessoa, ela deixa de ser particular porque ela é simbólica de uma gama infinita de relações. Cada parte do mundo nos dá certa presença, um ser próximo ou familiar, mas cada dimensão, uma ausência.

A pesquisa sobre a obra fenomenológica de Merleau-Ponty nos faz destacar a ideia de entrelaçamento, entre sujeito e mundo como partes integrantes de um mesmo tecido. Da mesma forma, propomos como expansão do conceito de espaço cênico o entrelaçamento do espectador com a encenação, uma relação que se dá num lugar específico durante uma duração determinada, um encontro onde um não se realiza sem o outro. 
A partir de diferentes situações de utilização do espaço cênico podemos pensar em uma consciência perceptiva do espectador que é corporal, ou seja, uma consciência que leva o espectador para o âmbito do "eu posso", um engajamento corporal com o mundo, realizando a noção de Merleau-Ponty do corpo como consciência, como escreveu Alvin na seguinte passagem:

A reflexão é corporal, falamos do corpo como região do "eu posso" e não do "eu penso", isto é, um corpo que lança o sujeito, quando em presença com os objetos do mundo, para uma circunvizinhança com as coisas e que the permite realizar uma síntese - apenas com um gesto dotado de alcance. Esta síntese o levaria daquilo que é dado para o que não é dado, mas está ali, na vizinhança, disponível, anunciando o futuro imediato, iminente. A isso o filósofo denominou, inspirado em Hussel, síntese de transição, síntese prática ou de horizonte, síntese que não é intelectual, mas corporal (Alvin, 2007, p. 180).

A relação entre o espectador, os outros espectadores, os atores, os elementos dramáticos, visuais e sonoros do espetáculo, resulta naquilo que chamamos de espaço cênico no teatro. Se há relação, o espectador, então, é elemento fundamental da encenação, não apenas conceitualmente, mas, fisicamente. O espectador é parte integrante do mesmo tecido que forma os demais elementos citados. O espectador age no espaço-tempo por meio de uma vivência corporal da encenação. A diretora teatral Anne Bogart escreveu que os atores são os grandes responsáveis pela criação desse ambiente de relação com o público, pois:

Essa capacidade de estimular o público a desejar, a experimentar o desejo mais do que saciá-lo, faz parte do trabalho do ator. [...]. O espectador deve ser atraído para o palco como um detetive na pista de um crime. [...]. O teatro acontece entre o espectador e o ator. A dinâmica entre um ator e o público constitui um relacionamento íntimo e distanciado ao mesmo tempo. [...]. O ator inicia e a plateia completa o círculo com sua imaginação, sua memória e sensibilidade criativa. Sem receptor não há experiência (Bogart, 2011, p. 74).

O espectador e o espetáculo juntos formam um todo indivisível, a "carne do mundo" para Merleau-Ponty, que no espetáculo é constituída tanto pelo espectador (sujeito), o vidente-visível, quanto pelo espaço (objeto), atores e pelos 
demais espectadores, ambos sujeitos videntes e visíveis, reversivelmente. Ambos são partes de um mesmo tecido, a carne do mundo. Este conceito da carne foi abordado por Merleau-Ponty, sobretudo, na sua obra póstuma $\bigcirc$ visível e o invisível, onde também a visão é, talvez, o mais importante sentido no ato perceptivo. Ele diz:

A carne não é matéria, não é espírito, não é substância. Seria preciso, para designá-la, o velho termo "elemento", no sentido em que era empregado para falar-se da água, do ar, da terra e do fogo, isto é, no sentido de uma coisa geral, meio caminho entre o indivíduo espácio-temporal e a ideia, espécie de princípio encarnado que importa um estilo de ser em todos os lugares onde se encontra uma parcela sua. Neste sentido a carne é um "elemento" do Ser. Não fato ou soma de fatos e, no entanto, aderência ao lugar e ao agora (Merleau-Ponty, 2014, p. 136).

O tecido no qual somos entrelaçados é um corpo onde sujeitos (espectadores) e objetos (encenações) habitam, mesmo que sejam opostos, pois, a carne é um tipo de dimensão estrutural estabelecida inicialmente. Somos parte de um mesmo tecido, a carne do mundo, pois, "a carne (a do mundo ou a minha) não é contingência, caos, mas textura que regressa a si e convém a si mesma" (Merleau-Ponty, 2014, p.138).

O espaço cênico, por sua vez, na duração do espetáculo, é vivido por mais de um espectador, mais de um sujeito vidente e visível, que individualmente experimenta suas vivências corporais e formulam os seus conceitos. $\mathrm{Na}$ perspectiva de um espaço cênico em formato alternativo, por exemplo, no qual os espectadores circulam pelo espaço livremente, há, para qualquer espectador, no seu campo de visão, outros espectadores que também o olham e formulam seus próprios conceitos. Ambos existem independentemente da vontade do outro. Há também os atores do espetáculo, que são vistos por ambos os espectadores e que também se relacionam com a audiência.

Merleau-Ponty apresentou a espacialidade sob duas perspectivas: o espaço posicionado e o espaço situado. 
O primeiro tem a ver com a posição e a localização dos objetos que estão no mundo, compreendidos como coisas, que só ganham sentido quando há um sujeito que as percebe. O conceito de espaço de posição, transposto para a encenação, tem a ver com a topografia do espaço, ou seja, a espacialidade criada pelos elementos cenográficos, como móveis, escadas, rampas, praticáveis, colunas e paredes cenográficas, ou seja, tudo aquilo que será percebido pelo espectador. A espacialidade de posição é o que se compreende por espaço geográfico, como dissemos. É o lugar onde o sujeito terá suas experiências concretas, onde perceberá o espaço através de suas formas, por exemplo. É uma espacialidade onde os objetos podem ser descritos pelo sujeito através de dados visuais, mensuráveis, pois, "o espaço não é o ambiente (real ou lógico) nem que as coisas se dispõem, mas o meio pelo qual a posição das coisas se torna possível" (Merleau-Ponty, 2006, p. 328).

Já o segundo espaço, o de situação, aborda uma compreensão na qual o sujeito não está apenas inserido no espaço, mas vive esta relação, experimentando a relação com os objetos, percebendo o mundo e ressignificando-o. Experimentar o percurso de distâncias ou afastamentos, por exemplo, faz com que o sujeito vivencie determinadas percepções. Nessa perspectiva da posição, Bollnow escreveu:

No espaço vivenciado, os caminhos com suas direções e distâncias também estão referidos aos objetivos para onde conduzem. Cada caminho é o caminho para alguma coisa mais ou menos distante, e somente essa referência faz dele um caminho. Esses pontos objetivos do caminho, contudo, têm para o homem algum significado, razão por que ele quer ir até eles - ou deles foge, pois não há somente lugares desejáveis, mas também lugares de perigo e do desconforto, de modo que também os caminhos de fuga e atalhos devam ser referidos no sistema dos caminhos (Bollnow, 2008, p. 218)

Transposto para o espaço cênico, o espaço de situação tem a ver com as sensações de cada espectador, sua afinidade espacial na duração cênica, tudo isso faz com que ele tenha uma experiência específica da vivência espacial no espetáculo, pois, o espectador vive o espaço. A espacialidade de situação é referente ao corpo que, como sistema de ações, vive uma experiência perceptível 
e, dessa maneira, é uma espacialidade que nunca deixa de estar em relação a quem percebe, como observou Figueiredo:

Enquanto no espaço de posição, o sujeito pode delimitar esquemas para direcionar localizações, na espacialidade de situação o sujeito não tem como meta definir localizações, pois ele mesmo habita o espaço em que está inserido; ele não é um objeto que se pode ser colocado em algum lugar da superfície terrestre. O corpo próprio é que define sua situação, é ele que modifica e resinifica todo o espaço situado porque, estando nele, habita-o (Figueiredo, 2015, p. 70).

A partir da distinção colocada, identificamos, por exemplo, que a espacialidade de situação tem a ver com a ideia de profundidade que é experimentada pelo agente na vivência do espaço. Situado no espaço cênico o espectador vivencia a imersão de um espaço que atua em diferentes camadas da percepção.

A profundidade, nesse sentido, não seria uma característica mensurável para o olhar que vivencia o espaço cênico, permitindo assim o que poderíamos chamar de uma autonomia do espaço.

A respeito do "espaço de situação" também podemos pensar os atributos sensoriais do espaço, aqueles que permitem ao espectador vivenciar qualidades espaciais pelos próprios sentidos. Nessa perspectiva, retomando o assunto das cores para abordar a sensorialidade espacial, citamos novamente Bollnow quando diz:

Cumpre mencionar que as cores tornam o espaço mais estreito ou mais vasto. Cores claras tornam o espaço não somente mais iluminado, mas também mais vasto; já as cores escuras o tornam estreito. Um teto negro tem algo de carregado, que chega a ser opressor, mas pode ao mesmo tempo conferir o caráter de unidade e um calor aconchegante. Isso vale também para cada qualidade cromática (Bollow, 2008, p. 248).

A noção de Quiasma traduz a relação do espectador com o ator, ampliando a noção de Reversibilidade. Porém, também podemos pensar que essa relação do espectador com o outro pode ser realizada de maneira interpessoal, ou seja, quando a experiência perceptiva do espetáculo pode ser compartilhada com 
outros espectadores. Pensamos assim em um "sentiente em geral”, formado por um grupo de espectadores, que se relaciona com um "sensível em geral", o espetáculo, compartilhando percepções, corporeidades. Nessa perspectiva, também pensamos o espaço cênico no teatro como um lugar de relação intercorporae, resultando numa percepção em concordância do corpo de um espectador com o corpo de outro, a partir de uma operação da existência e não de uma simples representação, pois:

Diz-se que as cores, os relevos tácteis de outrem são para mim um mistério absoluto, sendo-me inacessíveis para sempre. Isso não é totalmente verdadeiro, pois, para que eu deles tenha não uma ideia, uma imagem ou representação, mas como que a experiência iminente, basta que eu contemple uma paisagem, que fale dela com alguém: então, graças à operação concordante de seu corpo com o meu, o que vejo passa para ele, este verde individual da pradaria sob meus olhos, invadethe a visão sem abandonar a minha; reconheço em meu verde o seu verde [...]. Não sou eu que vejo, nem é ele que vê, ambos somos habitados por uma visibilidade anônima, visão geral, em virtude dessa propriedade primordial que pertence à carne de, estando aqui e agora, irradiar por toda parte e para sempre, de, sendo indivíduo, também ser dimensão e universal (Merleau-Ponty, 2014, p, 138).

Essa reflexão entre o eu e outro, esse mundo prévio que habitamos corporalmente e anonimamente, como escreve Merleau-Ponty, e o modo como o espaço cênico está estruturado, sempre mediado pela relação quiasmática do entrelaçamento entre o espectador e o ator.

O espectador, por ser o sujeito receptivo da relação, é anônimo, sua identidade não é revelada além dos atributos que sua presença instaura. Os demais espectadores, desconhecidos, também são anônimos. Quem se apresenta publicamente, são também anônimos que vão se revelando aos poucos, são os atores/personagens da ficção, concebidos pela encenação, porém, apresentam-se ao vivo, no aqui-agora para uma plateia de anônimos. De qualquer forma, o sujeito da percepção, para Merleau-Ponty, será sempre anônimo.

O corpo do espectador, para concluir, é uma potência dotada de percepção e expressão, razão pela qual se torna possível uma vivência estética. A vivência do espaço vai se revelando aos poucos, na medida em que o contato vai se formando, 
na medida em que os espectadores se impõem com suas presenças, seus desejos e suas proposições no espaço, que, por sua vez, também se impõe com seus atributos ao espectador.

A interface com a filosofia de Merleau-Ponty fundamenta as nossas proposições sobre o espaço relacional e nos assegura de que há ainda muito para se experimentar nas criações cênicas, principalmente a partir do uso e apropriação dos espaços e construções cenográficas sob essa perspectiva da vivência e da ressignificação por parte do espectador.

\section{Referências}

ALVIN, M. Ato artístico e ato psicoterápico como experimenta-ção: diálogos entre a fenomenologia de Merleau-Ponty, a arte de Lygia Clark e a Gestalt-Terapia. 2007. 387 f. Tese (Doutorado em Psicologia) - Instituto de Psicologia, Universidade de Brasília, Brasília, 2007.

ARAUJO, Paulo R. M. e CODINA, Graciela D. Leitura fenomenológica da arte e do ser humano aponta para a superação de sentido e a abertura de significados. Revista Filosofia, Ciência e Arte. Ano II, Vol. 8. São Paulo: Editora Nova Escala, 2007.

ARNHEIM, Rudolf. Arte e percepção visual: Uma psicologia da visão criadora. São Paulo: Pioneira Thomson Learning, 2005.

AZEVEDO, Sônia M. O corpo em tempos e lugares pós-dramáticos. In: O PósDramático. São Paulo: Perspectiva, 2010.

BACHELARD, Gaston. A Poética do Espaço. Os Pensadores XXXVIII. São Paulo: Abril Cultural, 1974.

BOGART, Anne. A preparação do diretor. São Paulo: Martins Fontes, 2011.

BOLLNOW, Otto F. O homem e o espaço. Trad. Aloísio Leoni Schmid. Curitiba: Editora UFPR, 2008.

DIDI-HUBERRMAN, Georges. O que vemos, o que nos olha. São Paulo: Editora 34, 2010.

CARDIN, Leandro Neves. A ambiguidade na Femenologia da percepção de Maurice Merleau-Ponty. 2007. Tese (Doutorado em Filosofia) Faculdade de Filosofia, Letras e Ciências Humanas da Universidade de São Paulo, São Paulo, 2007. 
COSTA, Maria E. A poesia do canto: Da fenomenologia de Bachelas a Graciliano Ramos. Verbo de Minas, Juiz de Fora, v. 17, n. 29. p. 30-46, jan./jul. 2016.

FALABRETTI, Ericson Sávio. Kant e Merleau-Ponty: Passagens sobre o espaço. Artigo publicado na Revista Internacional de filosofia Kant e-Prints. Campinas, série 2, v. 4, n. 1, p, 165-183, 2009. Disponível em:

$<$ https://www.cle.unicamp.br/eprints/index.php?journal=kant-e-

prints\&page=article\&op=view\&path\%5B\%5D=368> Acesso em: 05 abr. 2019

FALABRETTI, Ericson Sávio. A pintura como paradigma da percepção. Revista Dois Pontos, vol. 9, n. 1, p. 201-226, 2012. Disponível em:

< http://dx.doi.org/10.5380/dp.v9i1.25515> Acesso em 23/01/2019.

FIGUEIREDO, Jadismar de lima. Corpo próprio, especialidade e mundo percebido em Merleau-ponty. 2015. 130 f. Dissertação (Mestrado) - Universidade Federal da Paraíba, João Pessoa, 2015. Disponível em:

<http://tede.biblioteca.ufpb.br:8080/handle/tede/8345>

FORJAZ, Cibele. A linguagem da luz a partir do conceito de pós dramático desenvolvido por Hans-Thies Lehmann. In: QUINSBURG, J.; FERNANDES, Silvia (org.). O Pós-Dramático. São Paulo: Perspectiva, 2010.

LEHMANN, Hans-Thies. Teatro pós-dramático e teatro político. In: QUINSBURG, J.; FERNANDES, Silvia (org.). O Pós-Dramático. São Paulo: Perspectiva, 2010.

MERLEAU-PONTY, Maurice. Textos selecionados. Seleção de textos, tradução e notas de Marilena de Souza Chauí, Nelson Aguilar, Pedro de Souza Moraes. Segunda Edição. São Paulo: Abril Cultural, 1984.

MERLEAU-PONTY, Maurice. Fenomenologia da percepção. 3a ed. São Paulo: Martins Fontes, 2006.

MERLEAU-PONTY, Maurice. A prosa do mundo. São Paulo: Cosac Naify, 2012.

MERLEAU-PONTY, Maurice. O Visível e o Invisível. 4 ed. São Paulo: Perspectiva, 2014.

Recebido em: 24/08/2020

Aprovado em: 12/02/2021

Universidade do Estado de Santa Catarina - UDESC

Programa de Pós-Graduação em Teatro - PPGT

Centro de Arte - CEART

Urdimento - Revista de Estudos em Artes Cênicas

Urdimento.ceart@udesc.br 